OPEN ACCESS

Edited by:

Steve Suib,

University of Connecticut,

United States

Reviewed by:

Vasudevan Raghavan,

Indian Institute of Technology

Madras, India

Roman V. Fursenko,

Institute of Theoretical and Applied

Mechanics (RAS), Russia

*Correspondence:

Alexei Saveliev

asaveliev@ncsu.edu

Specialty section:

This article was submitted to Chemical and Process Engineering,

a section of the journal

Frontiers in Chemistry

Received: 27 August 2019

Accepted: 21 January 2020

Published: 11 February 2020

Citation:

Banerjee A and Saveliev A (2020)

Emission Characteristics of Heat

Recirculating Porous Burners With

High Temperature Energy Extraction.

Front. Chem. 8:67.

doi: 10.3389/fchem.2020.00067

\section{Emission Characteristics of Heat Recirculating Porous Burners With High Temperature Energy Extraction}

\author{
Abhisek Banerjee and Alexei Saveliev* \\ Department of Mechanical and Aerospace Engineering, North Carolina State University, Raleigh, NC, United States
}

Emission characteristics of heat recirculating porous burners with high temperature heat extraction are studied numerically. Two types of burners are considered: counterflow porous burner (CFB) and reciprocal counterflow porous burner (RCFB). The combustion of methane-air mixtures flowing through the porous media is modeled by solving steady state governing equations to obtain the flame temperature and species profiles. Formation of $\mathrm{CO}, \mathrm{NO}, \mathrm{NO}_{2}$, and $\mathrm{NO}_{x}$ is studied in CFB and $\mathrm{RCFB}$ in a range of equivalence ratios from 0.3 to 1.0 and heat extraction temperatures from 300 to $1,300 \mathrm{~K}$. The contribution of various NO formation mechanisms is comparatively analyzed and related to the NO generation predicted by a detailed chemistry mechanism. The effect of high temperature heat extraction on the formation of $\mathrm{CO}$ and $\mathrm{NO}_{\mathrm{x}}$ is analyzed. Numerical predictions indicate a constant monotonic decrease of $\mathrm{NO}_{x}$ concentration with increasing temperature of energy extraction. The formation of $\mathrm{CO}$ is observed to follow the similar trend. For heat extraction at $1,300 \mathrm{~K}$, simulations predicted $3.6 \mathrm{ppm}$ of $\mathrm{NO}_{\mathrm{x}}$ and $3.9 \mathrm{ppm}$ of $\mathrm{CO}$ for CFB and $4.1 \mathrm{ppm}$ of $\mathrm{NO}_{x}$ and $3.5 \mathrm{ppm}$ of $\mathrm{CO}$ for RCFB when these burners are operated at an equivalence ratio of 0.7 .

Keywords: porous combustion, combustion emissions, $\mathrm{NO}_{\mathrm{x}}$ formation, combustion kinetics, pollutant kinetics

\section{INTRODUCTION}

Oxides of nitrogen ( $\mathrm{NO}$ and $\mathrm{NO}_{2}$ ), also termed as $\mathrm{NO}_{\mathrm{x}}$, are well-known to be detrimental to the environment. Starting from ozone-depletion, photochemical smog to acid rain, these chemical compounds are responsible for many adversities to the environment and human life. $\mathrm{NO}_{\mathrm{x}}$ are generated from automobiles and industries involving thermal power generation and boilers. Nitrogen as a main air component is inevitably present in all the combustion systems. This makes combustion process a major contributor to the total concentration of atmospheric $\mathrm{NO}_{\mathrm{x}}$. In last few decades, many researchers have been working to study the mechanism of $\mathrm{NO}_{\mathrm{x}}$ generation in flames (Marteney, 1970; Iverach et al., 1973; Bowman, 1975; Miller and Bowman, 1989).

The formation of $\mathrm{NO}$ in combustion commonly follows three main routes: thermal (Zeldovich) mechanism, the prompt (Fenimore) mechanism and $\mathrm{N}_{2} \mathrm{O}$-intermediate mechanism. In addition, some researchers reported NO formation through NNH pathway (Bozzelli and Dean, 1995; Harrington et al., 1996; Hayhurst and Hutchinson, 1998; Klippenstein et al., 2011). Zeldovich (1946) described the $\mathrm{NO}$ formation through reactions $\mathrm{N}_{2}+\mathrm{O} \rightarrow \mathrm{NO}+\mathrm{O}, \mathrm{N}_{2}+\mathrm{O} \rightarrow \mathrm{NO}+\mathrm{N}$. He reported these reactions to be slower than other reactions taking place during combustion. The rate of $\mathrm{NO}$ formation is controlled by the second reaction, owing to the high activation energy of $314 \mathrm{~kJ} / \mathrm{mol}$. As a result, Zeldovich mechanism displays a strong dependence on temperature. 
Miller and Bowman (1989) confirmed that this mechanism is insignificant below 1,800 K. Fenimore (1971) presented a prompt mechanism closely linked with the combustion chemistry of hydrocarbons. He proposed a series of reactions leading to the fast formation of NO. NO formation through this mechanism takes place in the reaction zone. He concluded that the concentration of $\mathrm{CH}$ radicals is a significant factor affecting the total NO formation. Prompt mechanism is responsible for $\mathrm{NO}_{\mathrm{x}}$ formation at low temperatures (Dupont and Williams, 1998; Steele et al., 1998). As the name suggests, $\mathrm{N}_{2} \mathrm{O}$-intermediate $\mathrm{NO}$ formation proceeds through a set of reactions involving $\mathrm{N}_{2} \mathrm{O}$ (Miller and Bowman, 1989).

Despite the formation mechanisms of $\mathrm{NO}_{\mathrm{x}}$ are fairly wellknown, intrinsic control of its minimization is still a subject of extensive research. In this context, Takeno et al. (1981) and Kotani and Takeno (1982) devised the concept of inserting solid porous medium in the reaction zone of a premixed flame for achieving heat recirculation. They reported higher burning rates compared to that of free flames and observed lower emissions of $\mathrm{CO}$ and $\mathrm{NO}_{\mathrm{x}}$. Since then, many researchers (Khanna et al., 1994; Ellzey and Goel, 1995; Kennedy et al., 2002; Bingue et al., 2007; Bubnovich et al., 2007) have studied porous medium combustion using various designs of the burners to observe low emissions of $\mathrm{CO}$ and $\mathrm{NO}_{\mathrm{x}}$. Recently, Banerjee et al. (2019) studied a two-stage combustion system (combination of filtration and non-premixed combustion) and reported low $\mathrm{NO}_{\mathrm{x}}$ emissions. The unique characteristics of filtration combustion, such as strong interfacial heat transfer between solid and gas phase and enhanced gas phase dispersion of reactants and products (Kennedy et al., 2000), create a foundation for stable combustion over a wide range of reactant velocities, and fuel-air ratios. These attributes of filtration combustion have led to its potential applications in several domains like coating and paint drying, metal heat treatment, hydrogen and syngas synthesis, electricity generation (Marbach and Agrawal, 2005; Toledo et al., 2011, 2012; Bubnovich et al., 2016; Banerjee and Saveliev, 2018, 2019). Depending on the type of application, researchers have used various design of burners filled with porous medium like counterflow porous burner (CFB) (Belmont and Ellzey, 2014; Banerjee and Saveliev, 2018), reciprocal flow burner (RFB) (Contarin et al., 2003), and a combination of counterflow and reciprocal flow porous burners called as reciprocal counterflow porous burner (RCFB).

One of the novel applications of heat regenerating porous burners is related to portable power generation systems based on thermoelectric and thermionic generators and Stirling engines. The burners are incorporated in these systems to supply high temperature heat to electricity generators. High energy efficiency and low emission levels are the major requirements for the combustion devices used. Heat recirculating porous burners are the perfect candidates. The high energy efficiency in these burners is achieved by the internal heat regeneration. They are also known to have ultralow emission characteristics because of the extended low temperature combustion zones. Previous studies reported the effects of equivalence ratio and firing rate on the emission characteristics of the heat recirculating porous burners (Kennedy et al., 2002; Afsharvahid et al., 2008). However, the effect of the high temperature heat extraction on $\mathrm{NO}_{\mathrm{x}}$ and $\mathrm{CO}$ formation was not considered.

This article studies $\mathrm{NO}_{\mathrm{x}}$ and $\mathrm{CO}$ formation in a CFB and RCFB when heat is extracted from them at high temperatures. Various NO formation mechanisms are comparatively analyzed to understand the contribution of individual pathways to the total $\mathrm{NO}_{\mathrm{x}}$ generation. The effect of the heat extraction temperature on $\mathrm{NO}_{\mathrm{x}}$ and $\mathrm{CO}$ formation is considered to address feasibility of these burners for applications in portable power generators and other combustion systems.

\section{NUMERICAL MODEL}

\section{Model Geometry}

Two burners, namely CFB and RCFB, are studied for high temperature heat extraction. To simplify a comparative analysis, the numerical model considers the same physical geometry for the porous burner operating in CFB and RCFB modes. The twodimensional burner (Figure 1) has an active length of $200 \mathrm{~mm}$ and height of $25 \mathrm{~mm}$. The separation wall splits the burner in two channels. The wall transfers the heat between two channels providing heat recirculation between hot products and cold reactants. The wall is made of alumina. The porous medium is formed by a packed bed of solid spheres resulting in a porosity of $\sim 0.4$. The uniform porosity distribution is assumed by the model. The burner contains four tubular heat exchangers placed in the locations shown by circles in Figure 1. The heat exchangers are treated as walls maintained at a fixed temperature. The low temperature heat exchangers (LTHEs) operate at $300 \mathrm{~K}$ and positioned near the inlet and outlet of the burner. LTHS are always active and help to restrict flame inside the burner. The high temperature heat exchangers (HTHEs) operate at extraction temperatures varying from 300 to 1,300 K. HTHEs are activated based on the burner operation mode as described below. The placement of HTHEs is selected based on numerical optimization to achieve maximum energy extraction efficiency (Banerjee and Saveliev, 2018; Banerjee, 2019).

\section{CFB and RCFB Operation}

CFB is named to reflect the direction of fluid flow in the burner. During its passage through the burner, the fluid passes through a counter flow path (Figure 2A). The fuel/air mixture enters the inlet channel and gets preheated until it reaches the flame zone. The hot products leave the burner through the exhaust channel. The counterflow arrangement of fluid flow, results in heat regeneration between hot products and cold reactants.

Periodic switching of the direction of reactant flow is the basic principle of operation for a reciprocal flow burner. This flow reversal through the burner filled with solid porous medium, results in heat regeneration (Contarin et al., 2003). Using the concept of periodic flow reversal in CFB, a new type of burner named as RCFB was proposed by Banerjee (2019). In a RCFB, the direction of fluid flow is altered periodically to regenerate heat more efficiently than in a CFB. During flow reversal, the outlet of the burner is switched to inlet. This switching results in more efficient preheating of the reactants. The operation of RCFB is shown schematically in Figure 2B. 


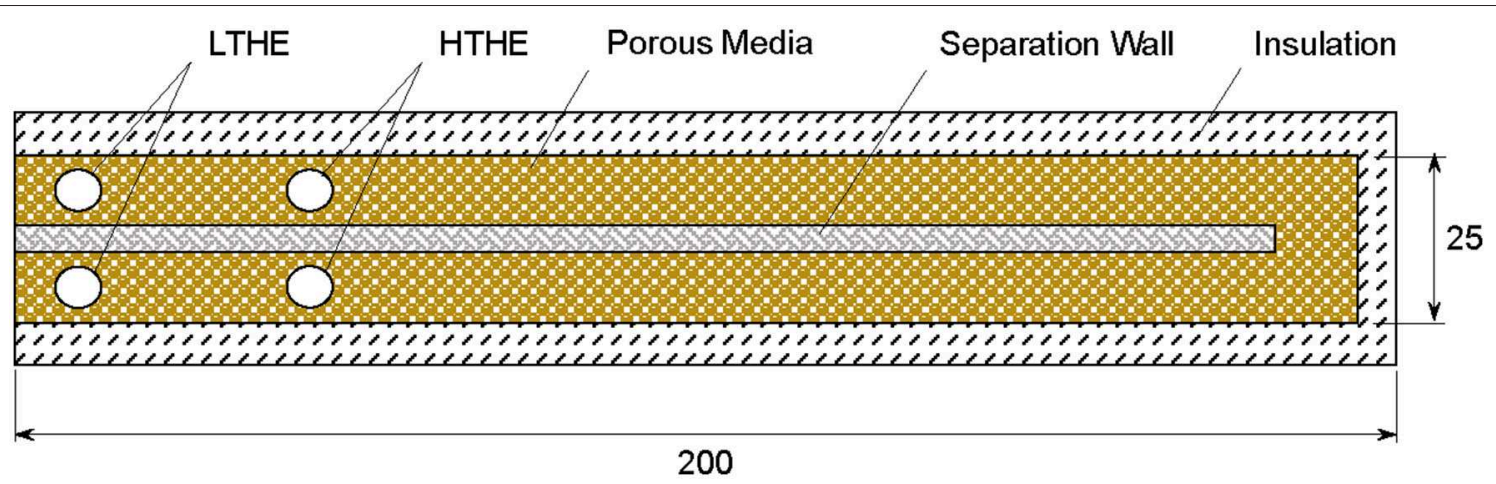

FIGURE 1 | Model geometry and schematic of the porous burner.

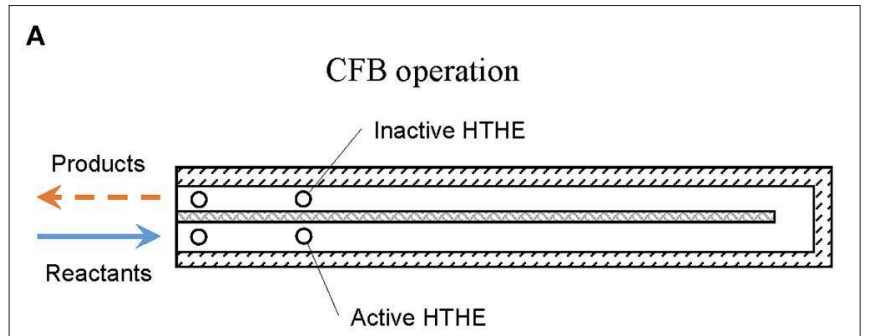

B

\section{RCFB operation}

\section{1 st half cycle}

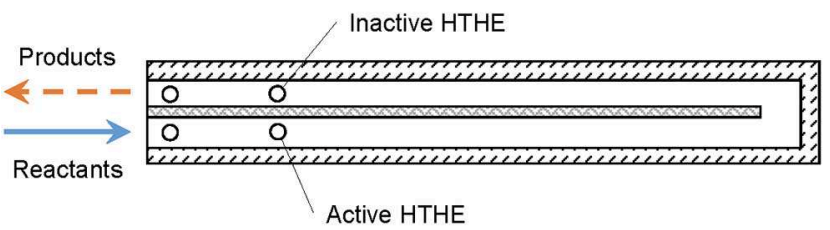

\section{$\underline{2}^{\text {nd }}$ half cycle}

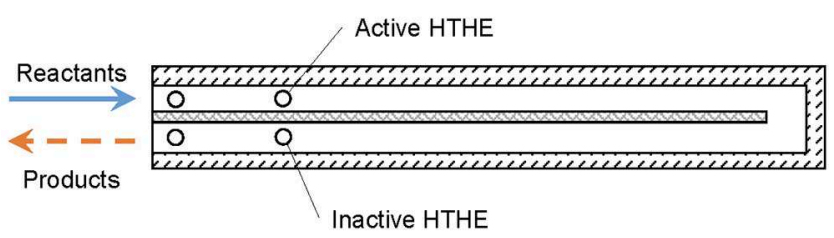

FIGURE 2 | Schematic representation of (A) CFB and (B) RCFB operation modes. Arrows indicate direction of flow.

\section{Computational Model}

The model used to simulate combustion in CRB and RCFB is based on the following assumptions: (i) the pressure drop in the burners is negligible, (ii) the gas and solid phases are in thermal equilibrium, (iii) radiation heat transfer in the gas phase is negligible compared to that in the solid phase, (iv) porous medium is chemically inert.
The numerical simulation of CFB is based on steady state solution of governing equations for a fully developed flow through porous medium. The details of the continuity, momentum, energy, and species equations is provided by Banerjee and Saveliev (2018). For this study, the numerical model accounts for conduction, convection, and radiation heat transfer.

RCFB burner works on the principle of heat regeneration by periodic flow reversal in a counterflow porous burner. The numerical model to study the unsteady behavior of a system having periodic flow reversal is very computationally expensive. Hence, to simulate quasi-steady behavior of RCFB, a timeaveraged approach (Yao and Saveliev, 2018) is adopted. The timeaveraged computational model of an RCFB system considers two CFBs having opposite directions of the gas flow and placed in thermal contact with each other. This model able to mimic the quasi-steady state behavior of the RCFB system. Detailed description of the computational model RCFB is available elsewhere (Banerjee, 2019).

A set of boundary conditions is imposed on the numerical model for simulating combustion and high temperature heat extraction. The inlet for the burner is treated as velocity inlet. The superficial velocity of the reactant mixture kept constant at $0.36 \mathrm{~m} / \mathrm{s}$ for this study. The outlet of the burner is set as pressure outlet. The external burner walls are considered adiabatic. The heat extraction from the burner through heat exchangers is calculated based on temperature difference between adjacent cells. The value thus obtained, is integrated over the complete domain of the heat exchanger.

\section{Chemical Mechanism}

Chemical mechanism plays a significant role in simulating combustion process in a burner. Be it evolution of temperature inside the burner or concentration of chemical species, chemical mechanism contributes significantly in a numerical simulation. Single-step chemical mechanisms have the advantage of predicting the combustion process in relatively lesser time than detailed mechanisms. However, they lack accuracy in many aspects such as species concentrations. In order to study the chemistry of $\mathrm{NO}_{\mathrm{x}}$ production, a detailed chemical mechanism is required for accurate prediction of temperature profile and 
concentration of various chemical species formed as a result of combustion. Hence, for this study one of well-known detailed chemical mechanisms GRI 3.0 (Smith et al., 2009) is used for simulating combustion. This mechanism comprises of 53 chemical species and 325 reactions.

\section{Solution Procedure}

The numerical simulations in this study are performed using Fluent 14.5. The governing equations are solved with steadystate approximation using a pressure-based solver. This solver uses an iterative approach to achieve convergence through a continuous loop. Absolute velocity formulation is used to predict combustion numerically. The numerical simulation is performed in laminar flow regime. Pressure and velocity are coupled using SIMPLE scheme. The energy, momentum and species equations are discretized using second order upwind scheme.

A grid independence study performed on numerical models of CFB and RCFB shows strong variation of maximum flame temperature when the number of grids was in a range from 200 thousand to 400 thousand. However, as the number of grids is increased beyond 600 thousand, the variations decreased largely. For CFB the stable grid independent temperature was obtained beyond 600 thousand, however, for RCFB the same is reached for grids with more than 800 thousand cells. Hence, the numerical simulations for CFB and RCFB were conducted with 860 thousand and 925 thousand cells, respectively.

\section{RESULTS AND DISCUSSION}

Flame temperature is one of the most important characteristics of the porous medium combustion. Figure 3 shows the maximum flame temperature predicted by the current model for CFB, $\mathrm{RCFB}$, and a freely propagating combustion wave in the tubular burner configuration studied by Kennedy et al. (2000). The numerical predictions for the maximum flame temperature in Kennedy's burner agree well with the experimental data reported by Kennedy et al. (2000). In porous combustion with heat recovery, the maximum flame temperature shows only weak dependence on the energy content of the mixture. The flame zone is free to position itself in the porous medium to achieve optimal heat recirculation. The porous medium conducts and radiates the heat from the flame zone to the relatively cooler zones inside the burner. This process of heat transfer restricts a significant rise in maximum flame temperature with increase of the equivalence ratio. In contrast to homogeneous flames, the maximum combustion temperature is mainly defined by the kinetics of combustion and heat transfer characteristics. Figure 3 also shows the maximum flame temperatures for CFB and RCFB. These temperatures are very close to the temperatures for the freely propagating wave and demonstrate only moderate increase with rise in equivalence ratio. For a specific equivalence ratio, the maximum flame temperatures are predicted for RCFB and almost the same for the CFB and the freely propagating combustion wave. This difference is mainly attributed to the effect of flow reversal in the RCFB.

It is also important to validate model predictions for $\mathrm{NO}_{\mathrm{x}}$ against published experimental data. The comparison of the

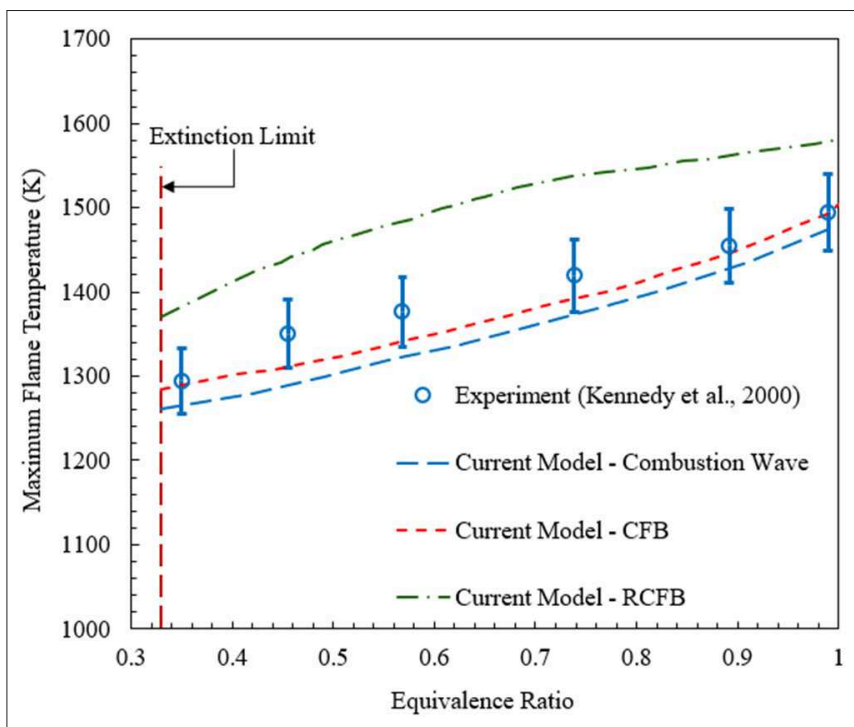

FIGURE 3 | Maximum flame temperatures predicted by the numerical model for CFB, RCFB, and freely propagating combustion waves. Experimental data for freely propagating combustion waves in a tubular reactor (Kennedy et al., 2000) are plotted for comparison. The superficial velocity is equal to $0.36 \mathrm{~m} / \mathrm{s}$.

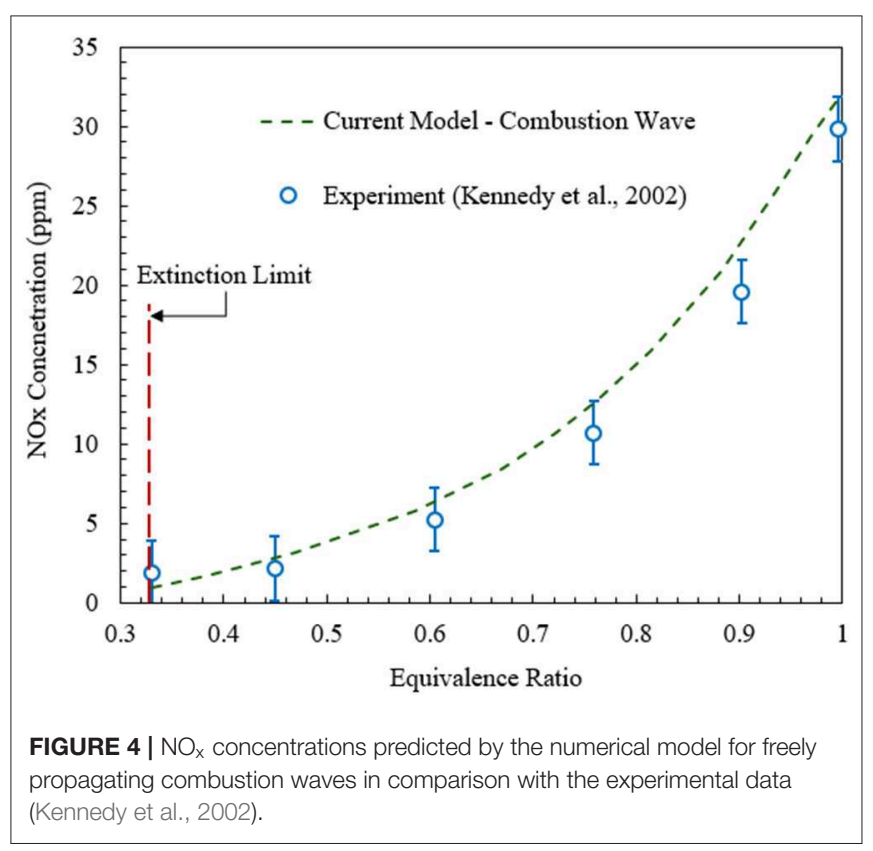

numerical predictions for the freely propagating combustion wave model and experimental data (Kennedy et al., 2002) is shown in Figure 4. Numerical simulations show that for ultralean combustion $\mathrm{NO}_{\mathrm{x}}$ formation is insensitive to the change in equivalence ratio. However, for $\phi>0.4 \mathrm{NO}_{\mathrm{x}}$ concentration increases rapidly with the rise in equivalence ratio. Overall, as confirmed by Figures 3, 4, the numerical predictions of the model used in this study agree well with the experimental results in terms of the maximum flame temperature and $\mathrm{NO}_{\mathrm{x}}$ concentration. 

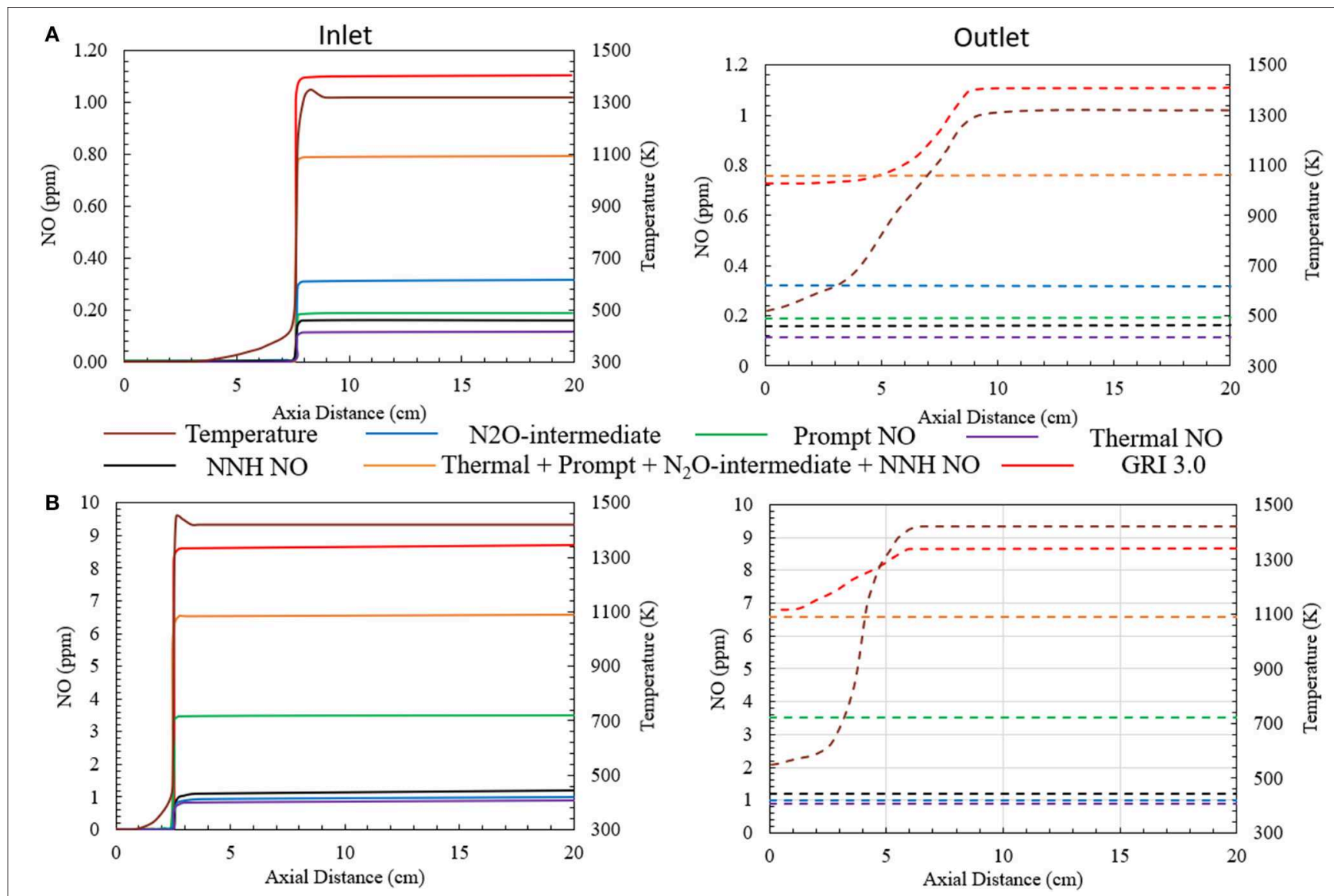

FIGURE 5 | NO formation via various major NO generating mechanisms for (A) $\phi=0.4$ (ultralean mixture) and (B) $\phi=0.7$ (lean mixture). Superficial velocity of reactants is maintained at $0.36 \mathrm{~m} / \mathrm{s}$. The HTHEs are inactive.

Major NO formation routes have been studied for heat recirculating porous burner using numerical predictions. The study is performed for the CFB operating at $\phi=0.4$ (ultralean) and $\phi=0.7$ (lean). The HTHEs are not activated. In Figure 5, the NO profiles are shown along the axial direction of the inlet and outlet channels. The left-hand side represents the inlet channel and the right-hand side shows the outlet channel. The contribution of various NO formation mechanisms toward the total $\mathrm{NO}$ emitted by the burner is shown. The NO concentrations generated by individual mechanisms, the total $\mathrm{NO}$ concentration (thermal + prompt $+\mathrm{N}_{2} \mathrm{O}+$ $\mathrm{NNH}$ ), and the NO concentration predicted by GRI 3.0 are reported.

For the ultralean condition $(\phi=0.4)$, the NO concentration predicted by the numerical model is slightly less than $1 \mathrm{ppm}(0.73$ ppm) at the burner outlet by GRI 3.0. The NO formation through thermal, prompt, $\mathrm{N}_{2} \mathrm{O}$-intermediate and $\mathrm{NNH}$ mechanisms is shown in Figure 5A. The $\mathrm{N}_{2} \mathrm{O}$-intermediate mechanism is dominant. The prompt and $\mathrm{NNH}$ mechanisms jointly contribute comparable amount of NO. However, the contribution of thermal NO mechanism is negligible compared to other pathways studied here. The direct summation of all the NO generation pathways leads to the NO concentration of $0.77 \mathrm{ppm}$ (Figure 5A) well below the predictions of GRI 3.0 for the high temperature region of the burner. However, the NO concentrations predicted by the chemical mechanism combining the individual NO generating mechanisms differ from GRI 3.0 by a very insignificant margin of $\sim 0.05 \mathrm{ppm}$. Concurrently, simulating this ultra-lean porous combustion with GRI 3.0 mechanism exhibits a decrease in the concentration of NO near the exit of the burner where the temperature drops. This is mainly because a part of the NO formed inside the burner transforms to $\mathrm{NO}_{2}$ before exiting the burner. As a result, GRI 3.0 predicts NO formation of $0.73 \mathrm{ppm}$ at the exit of the burner.

Figure 5B shows similar plot for the combustion of a lean methane/air mixture at $\phi=0.7$. In this case, the numerical simulation predicts an increase in the concentration of NO formed inside the burner. The prompt NO formation mechanism is observed to be the major contributor to the total NO formation. The NO concentration formed through the prompt mechanism is close to $3.5 \mathrm{ppm}$. This is mainly because the high concentration of hydrocarbons in the reactant mixture increases the concentration of $\mathrm{C}, \mathrm{CH}$, and $\mathrm{CH}_{2}$ radicals that govern NO formation through the prompt mechanism. Whereas, the other mechanisms like thermal, $\mathrm{N}_{2} \mathrm{O}$-intermediate and $\mathrm{NNH}$ mechanism produce approximately 1 ppm NO individually. 


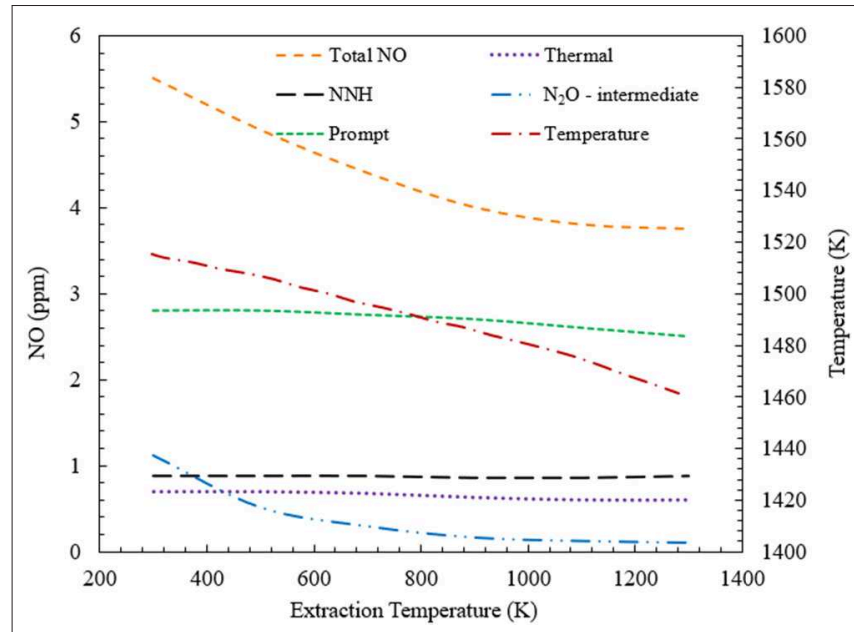

FIGURE 6 | Contribution of various NO formation mechanisms toward the total NO formation inside a CFB. This variation is studied for CFB when the energy extraction temperature is varied from 300 to $1,300 \mathrm{~K}$ at $\phi=0.7$.

Numerical simulation predicts a decrease in total $\mathrm{NO}$ concentration, with increase in the heat extraction temperature.

The summation of all the NO generating mechanisms leads to a total NO concentration of $6.5 \mathrm{ppm}$. GRI 3.0 predicts $6.65 \mathrm{ppm}$ of $\mathrm{NO}$ at the burner outlet. Corresponding to the previous case, GRI 3.0 mechanism shows a decrease in the $\mathrm{NO}$ concentration near the outlet of the burner, owing to the conversion of $\mathrm{NO}$ to $\mathrm{NO}_{2}$. Likewise, the deviation between the NO formation predicted by the combination of all the NO generating mechanism and that by GRI 3.0 in observed to be insignificant.

GRI 3.0 mechanism predicts a decrease in NO concentration near the burner outlet. The NO generation occurs mainly in the flame zone, with a negligibly small fraction generated in the post flame region. The temperature near the burner outlet decreases. This decrease in the temperature leads to NO being converted to $\mathrm{NO}_{2}$. Bowman (1975) reported the primary conversion reaction as $\mathrm{NO}+\mathrm{HO}_{2} \leftrightarrow \mathrm{NO}_{2}+\mathrm{OH}$. The difference in the concentration of total $\mathrm{NO}$ (thermal + prompt $+\mathrm{N}_{2} \mathrm{O}+\mathrm{NNH}$ ) and GRI 3.0 is related to the NO conversion near the outlet. The numerical concentrations of $\mathrm{NO}$ reported at the manuscript correspond to the NO concentration predicted by GRI 3.0 at the outlet of the burner.

Figure 6 shows the variation of NO generation through four major pathways, when heat is extracted from the CFB. For $\phi$ $=0.7$, the heat extraction temperature is varied from 300 to $1,300 \mathrm{~K}$ for the CFB. Numerical simulation predicts a decrease in the total NO formation with increase in heat extraction temperature. This decrease is mainly driven by the reduction of $\mathrm{NO}$ formed through $\mathrm{N}_{2} \mathrm{O}$-intermediate mechanism. However, there is a little decrease in the NO formation through the prompt mechanism. This is explained in detail in the following section of the manuscript. For CFB operating at $\phi=0.7$, the NO concentration is predicted to drop from $5.5 \mathrm{ppm}$ to nearly $4 \mathrm{ppm}$.
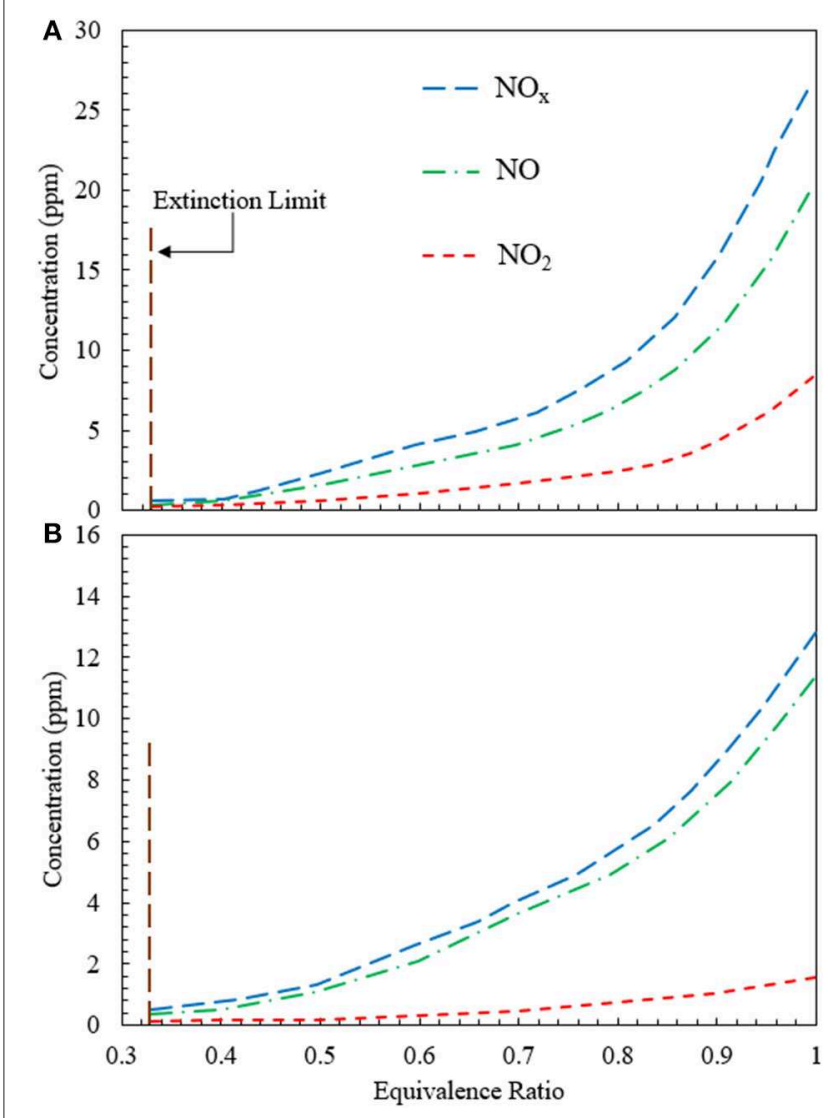

FIGURE 7 | Variation of $\mathrm{NO}, \mathrm{NO}_{2}$, and $\mathrm{NO}_{\mathrm{x}}$ concentration generated in the CFB when energy is extracted at (A) $500 \mathrm{~K}$ and (B) $1,100 \mathrm{~K}$. The concentrations of $\mathrm{NO}, \mathrm{NO}_{2}$, and $\mathrm{NO}_{x}$ rise when the equivalence ratio is increased from the extinction limit ( $\phi \approx 0.33$ ) to stoichiometry $(\phi=1)$. The superficial velocity of reactant mixture is $0.36 \mathrm{~m} / \mathrm{s}$.

The variation of $\mathrm{NO}_{\mathrm{x}}$ concentration as a function of equivalence ratio is studied for CFB when heat is extracted at 500 and $1,100 \mathrm{~K}$ (Figure 7). For the extraction at $500 \mathrm{~K}$, NO concentration increases monotonically from $0.4 \mathrm{ppm}$ at $\phi=0.3$ to $18.2 \mathrm{ppm}$ at $\phi=1.0$. The increase in NO remains insignificant until $\phi=0.4$. However, for $0.4<\phi<1.0$, NO concentration demonstrates a steady increase. The variation of $\mathrm{NO}_{2}$ appears to be similar to the $\mathrm{NO}$ profile. However, the concentration of $\mathrm{NO}_{2}$ is lesser than that of $\mathrm{NO}$ for the entire range of equivalence ratios studied. Numerical simulation predicts that $\mathrm{NO}_{2}$ concentration varies from $0.1 \mathrm{ppm}$ at $\phi=0.33$ to $8 \mathrm{ppm}$ at $\phi=1.0$, as shown in Figure 7A. The variation of $\mathrm{NO}_{\mathrm{x}}$ concentration remains similar to that of $\mathrm{NO}$ and $\mathrm{NO}_{2}$. For CFB with heat extraction at $500 \mathrm{~K}$, the $\mathrm{NO}_{\mathrm{x}}$ concentration varies from 0.5 to $26.2 \mathrm{ppm}$ for 0.33 $<\phi<1.0$. Figure 7B shows the plot for $\mathrm{NO}_{\mathrm{x}}$ concentration when heat is extracted at $1,100 \mathrm{~K}$. Similar to the previous case of heat extraction at $500 \mathrm{~K}$, the variations of $\mathrm{NO}, \mathrm{NO}_{2}$, and $\mathrm{NO}_{\mathrm{x}}$ show similar trend. However, for extraction at $1,100 \mathrm{~K}$, the concentrations of $\mathrm{NO}, \mathrm{NO}_{2}$, and $\mathrm{NO}_{\mathrm{x}}$ is lower than that at $500 \mathrm{~K}$. Numerical simulations show that for the heat extraction at $1,100 \mathrm{~K}$, the concentration of $\mathrm{NO}_{\mathrm{x}}$ increases from 0.4 to 11.65 $\mathrm{ppm}$ at the range of equivalence ratios from 0.33 to 1.0. 

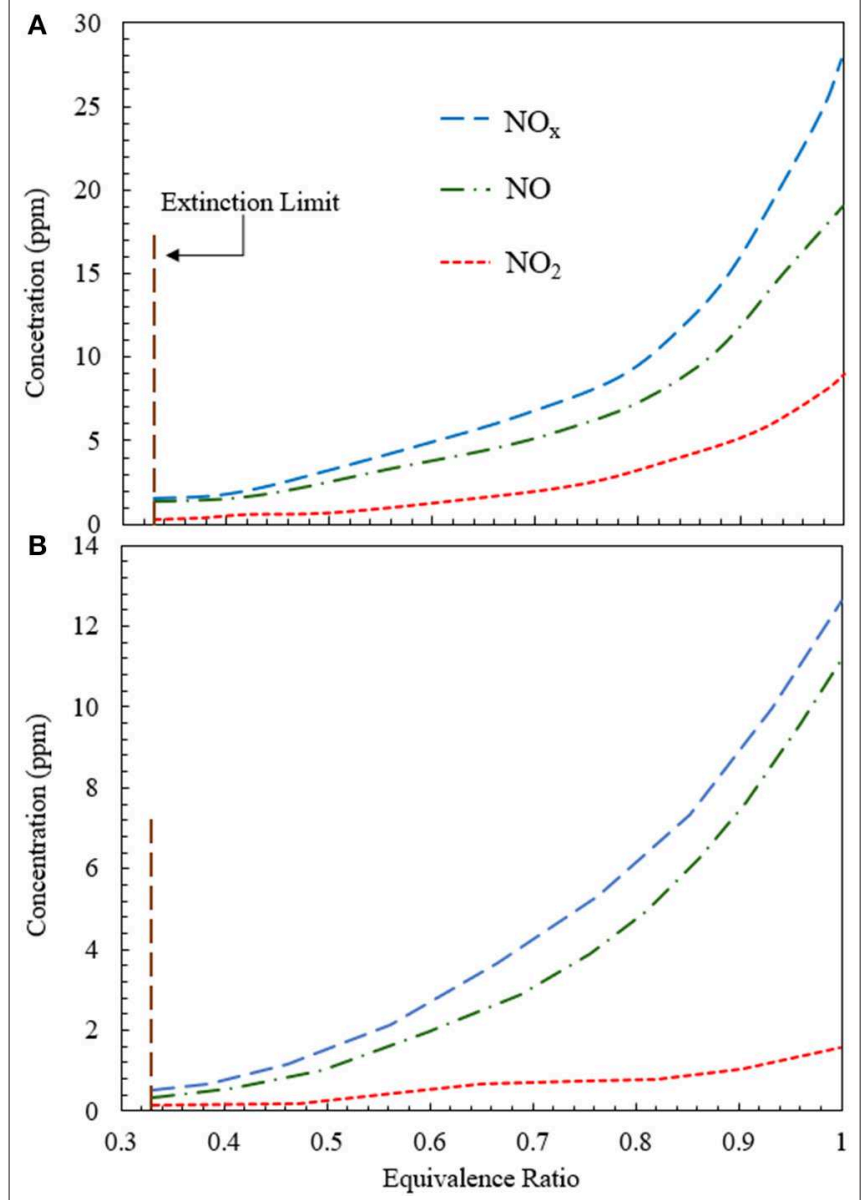

FIGURE 8 | Variation of $\mathrm{NO}, \mathrm{NO}_{\mathrm{s}}$, and $\mathrm{NO}_{x}$ concentration for RCFB as a function of equivalence ratio when heat is extracted at (A) $500 \mathrm{~K}$ and (B) $1,100 \mathrm{~K}$. The concentrations of $\mathrm{NO}, \mathrm{NO}_{2}$, and $\mathrm{NO}_{x}$ increase with rise in equivalence ratio from the extinction limit $(\phi \approx 0.33)$ to stoichiometry $(\phi=1)$. The superficial velocity of reactant mixture is kept at $0.36 \mathrm{~m} / \mathrm{s}$.

Figure 8 illustrates the variation of $\mathrm{NO}_{\mathrm{x}}$ concentration for heat extraction at 500 and $1,100 \mathrm{~K}$ using an RCFB. Figure 8A shows that $\mathrm{NO}_{2}$ concentration does not change appreciably for $0.33<\phi<0.5$. After $\phi=0.5, \mathrm{NO}_{2}$ concentration increases monotonically. Numerical simulation predicts $\mathrm{NO}_{2}$ values in the range from 0.2 to $7.8 \mathrm{ppm}$ for $0.33<\phi<1.0$. The NO concentration varies from 0.33 to $20.2 \mathrm{ppm}$ and that of $\mathrm{NO}_{\mathrm{x}}$ increases from 0.5 to $27.9 \mathrm{ppm}$ for $0.33<\phi<1.0$ (Figure 8A). The concentrations of $\mathrm{NO}, \mathrm{NO}_{2}$, and $\mathrm{NO}_{\mathrm{x}}$ are lower for heat extraction at $1,100 \mathrm{~K}$ than that at $500 \mathrm{~K}$. Numerical model shows that $\mathrm{NO}_{2}$ concentration varies between 0.1 and $1.7 \mathrm{ppm}, \mathrm{NO}$ concentration remains within the range from 0.3 to $11.1 \mathrm{ppm}$ and $\mathrm{NO}_{\mathrm{x}}$ concentration increases from 0.4 to $12.8 \mathrm{ppm}$ when the equivalence ratio is increased from 0.33 to 1.0 (Figure 8B).

Figure 9 shows the variation of $\mathrm{NO}_{\mathrm{x}}$ generated in $\mathrm{CFB}$ and $\mathrm{RCFB}$ as a function of the heat extraction temperature. The study is conducted for CFB and RCFB operating at $\phi=0.7$. Numerical predictions show that $\mathrm{NO}_{\mathrm{x}}$ concentration decreases from 6 to 3.6

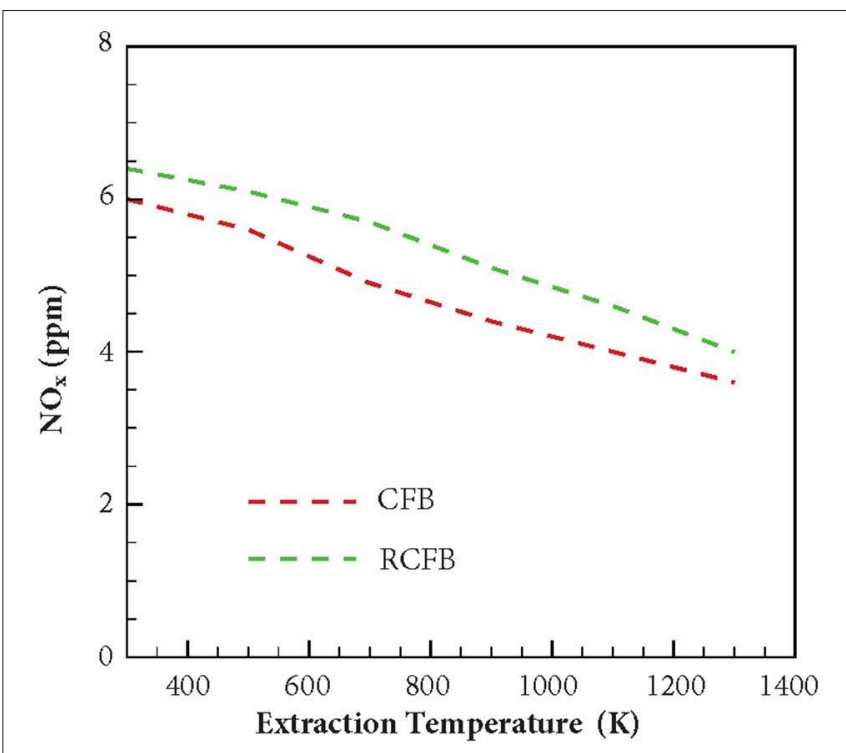

FIGURE 9 | Variation of $\mathrm{NO}_{x}$ concentration for CFB and RCFB as a function of energy extraction temperature. $\mathrm{NO}_{x}$ concentration decreases for $\mathrm{CFB}$ and RCFB with increase in energy extraction temperature. The burners are operated at $\phi=0.7$ with a superficial velocity of $0.36 \mathrm{~m} / \mathrm{s}$.

ppm for CFB when the heat extraction temperature is increased from 300 to $1,300 \mathrm{~K}$. Similarly, for RCFB the amount of $\mathrm{NO}_{\mathrm{x}}$ generated decreases from 6.4 to $4.1 \mathrm{ppm}$ for the same range of heat extraction temperatures. It is interesting to note that the amount of $\mathrm{NO}_{\mathrm{x}}$ generated for RCFB is more than that of CFB for the entire range of heat extraction temperatures.

The variation of maximum flame temperature of $\mathrm{CFB}$ and RCFB is shown in Figure 10. For both CFB and RCFB the maximum flame temperature decreases with increase in the heat extraction temperature. In case of CFB this decrease in maximum flame temperature is between 1,515 and $1,460 \mathrm{~K}$ when the heat extraction temperature rises from 300 to $1,300 \mathrm{~K}$. However, for $\mathrm{RCFB}$ this decrease in maximum flame temperature is from 1,580 to $1,505 \mathrm{~K}$. Thus, it can be inferred that for the entire range of heat extraction temperatures studied here, the maximum flame temperature for RCFB is higher than that of CFB. This results in higher NO formation through thermal mechanism in RCFB. Since the equivalence ratio of the fuel mixture entering the burner is the same for CFB and RCFB, the decrease in $\mathrm{NO}_{\mathrm{x}}$ formation in CFB is the result of lower NO formation through thermal mechanism in CFB than that in RCFB. A comparison of Figures 9, 10 shows that the variations of $\mathrm{NO}_{\mathrm{x}}$ concentration for CFB and RCFB with heat extraction temperature follow a trend similar to the one followed by maximum flame temperature vs. heat extraction temperature for the burners.

Similar to $\mathrm{NO}_{\mathrm{x}}$, variation of $\mathrm{CO}$ concentration is studied for $\mathrm{CFB}$ and RCFB when the heat extraction temperature is varied between 300 and 1,300 K (Figure 11). The burners are operated with fuel/air mixture at $\phi=0.7$. For CFB, increasing the heat extraction temperature from 300 to $1,300 \mathrm{~K}$ lowers the $\mathrm{CO}$ formation from 16 to $3.9 \mathrm{ppm}$. Whereas, energy extraction in 


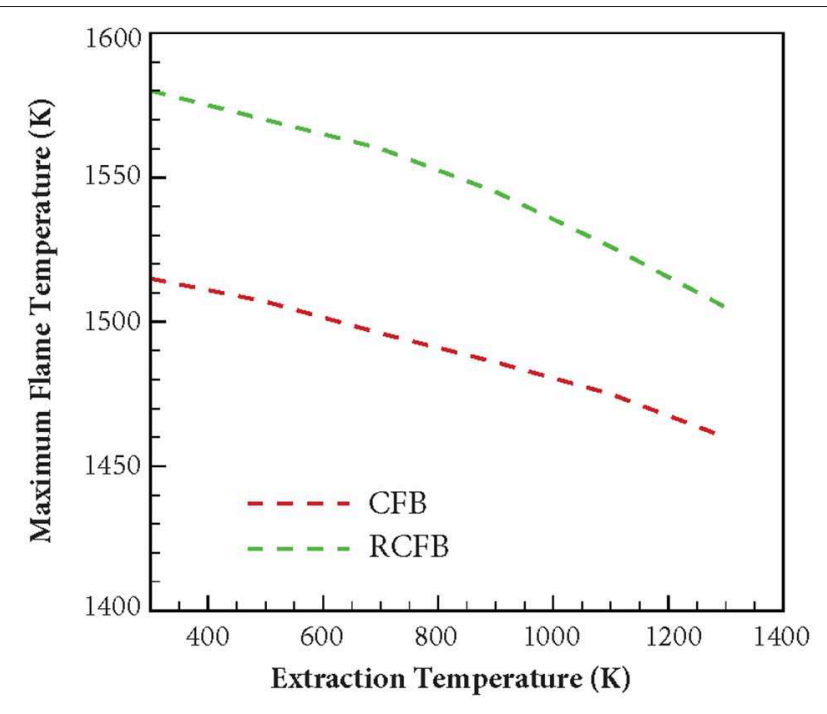

FIGURE 10 | Variation of maximum flame temperature for CFB and RCFB when heat is extracted at high temperature. Maximum flame temperature decreases with increase in heat extraction temperature in a way similar to decrease in $\mathrm{NO}_{x}$ concentration. The burners are operated at $\phi=0.7$ with a superficial velocity of $0.36 \mathrm{~m} / \mathrm{s}$.

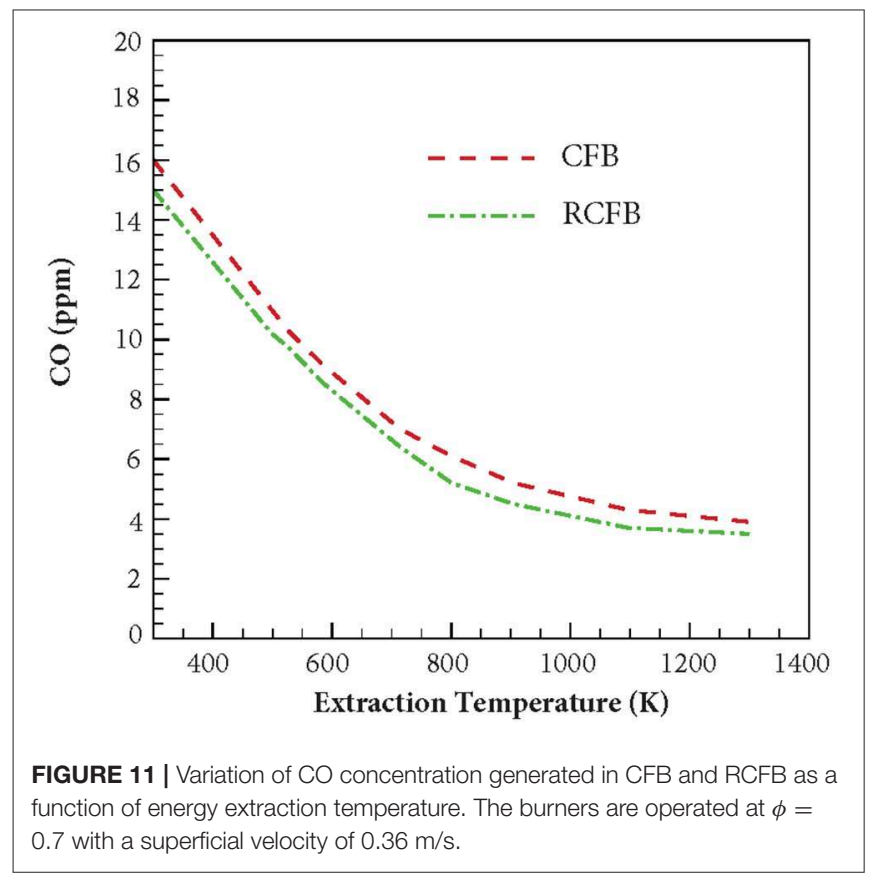

RCFB within this temperature range results in $\mathrm{CO}$ concentration to drop from 15 to $3.5 \mathrm{ppm}$. Similar to the trend of $\mathrm{NO}_{\mathrm{x}}$ formation, $\mathrm{CO}$ concentration reduces with increase in the heat extraction temperature.

Figure 12 shows the variation of $\mathrm{CO}$ concentration for $\mathrm{CFB}$ and RCFB as a function of equivalence ratio when energy is extracted at 500 and $1,100 \mathrm{~K}$. For energy extraction at $500 \mathrm{~K}$, the $\mathrm{CO}$ concentration increases from 1.4 to $41 \mathrm{ppm}$ when the

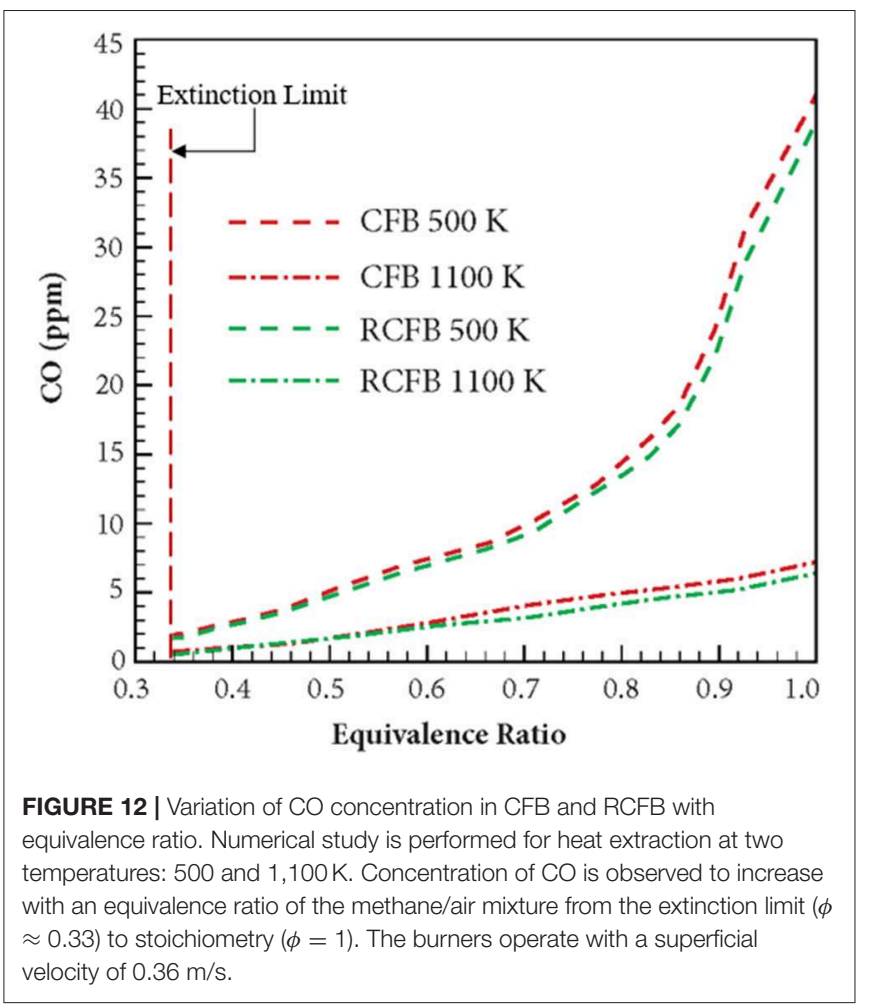

equivalence ratio increases from 0.33 to 1.0. This trend remains unchanged for RCFB as the $\mathrm{CO}$ concentration is observed to increase from 1.2 to $39 \mathrm{ppm}$. This increase of CO concentration can be attributed to the increase in hydrocarbon concentration in the fuel mixture with increase in equivalence ratio. Similarly, for energy extraction at $1,100 \mathrm{~K}$, the $\mathrm{CO}$ concentration increases from 0.6 to $7.2 \mathrm{ppm}$ for CFB and 0.4-6.4 ppm for RCFB when equivalence ratio is increased from 0.33 to 1.0 . Similar to the behavior of $\mathrm{NO}_{\mathrm{x}}$ concentration, $\mathrm{CO}$ concentration is observed to decrease when the heat extraction temperature increases. The trend remains valid for the range of equivalence ratio studied in this work.

\section{CONCLUSIONS}

This article presents the results from numerical investigation of the emission characteristics of CFB and RCFB when energy is extracted from these burners at high temperature. Various NO generation routes are analyzed to establish the relative contribution of these mechanisms in the total NO concentration emitted from the burner. It is found that amongst the four major NO producing mechanisms namely thermal mechanism, prompt mechanism, $\mathrm{N}_{2} \mathrm{O}$-intermediate mechanism and $\mathrm{NNH}$ pathway, the $\mathrm{N}_{2} \mathrm{O}$-intermediate mechanism is the major contributor for NO formation when ultralean mixtures are burned. However, for the combustion of lean mixtures prompt mechanism gains dominance over other routes. This is mainly because increase in the hydrocarbon concentration raises the concentration of $\mathrm{C}, \mathrm{CH}$, and $\mathrm{CH}_{2}$ radicals, which are major chemical species 
responsible for NO generation through prompt mechanism. The simulation results for the CFB and RCFB show that the $\mathrm{NO}_{\mathrm{x}}$ generated by RCFB is more than that of CFB by approximately $1 \mathrm{ppm}$ in all the cases studied here. This is mainly because of the higher maximum flame temperatures for RCFB than $\mathrm{CFB}$ leading to higher $\mathrm{NO}_{\mathrm{x}}$ formation through thermal mechanism. It has been observed that with increase of energy extraction temperatures, $\mathrm{NO}_{\mathrm{x}}$ concentration decreases for both heat recirculating porous burners studied here. This is attributed to the decrease in the maximum flame temperatures of CFB and RCFB with an increase in heat extraction temperature. This decrease in temperature diminishes the contribution of $\mathrm{N}_{2} \mathrm{O}$ intermediate mechanism and prompt mechanism and ultimately lowers the total $\mathrm{NO}_{\mathrm{x}}$ generated. Numerical results predicted that the maximum flame temperatures decreases in a way similar to the $\mathrm{NO}_{\mathrm{x}}$ concentration. Similar variation is observed

\section{REFERENCES}

Afsharvahid, S., Ashman, P. J., and Dally, B. B. (2008). Investigation of $\mathrm{NO}_{x}$ conversion characteristics in a porous medium. Combust. Flame 152, 604-615. doi: 10.1016/j.combustflame.2007.06.017

Banerjee, A. (2019). High temperature heat extraction from heat recirculating porous burner ( $\mathrm{PhD}$ thesis). North Carolina State University, Raleigh, NC, United States.

Banerjee, A., Kundu, P., Gnatenko, V., Zelepouga, S., Wagner, J., Chudnovsky, Y., et al. (2019). $\mathrm{NO}_{\mathrm{x}}$ minimization in staged combustion using rich premixed flame in porous media. Combust. Sci. Technol. doi: 10.1080/00102202.2019.1622532

Banerjee, A., and Saveliev, A. V. (2018). High temperature heat extraction from counterflow porous burner. Int. J. Heat Mass Transf. 127, 436-443. doi: 10.1016/j.ijheatmasstransfer.2018.08.027

Banerjee, A., and Saveliev, A. V. (2019). "Effect of heat extraction on flame position in counterflow porous burner," in 4th Thermal and Fluids Engineering Conference (Las Vegas, NV).

Belmont, E. L., and Ellzey, J. L. (2014). Lean heptane and propane combustion in a non-catalytic parallel plate counter-flow reactor. Combust. Flame 161, 1055-1062. doi: 10.1016/j.combustflame.2013.10.026

Bingue, J. P., Saveliev, A. V., and Kennedy, L. A. (2007). NO reburning in ultrarich filtration combustion of methane. Proc. Combust. Inst. 31, 3417-3424. doi: $10.1016 /$ j.proci.2006.07.257

Bowman, C. T. (1975). Kinetics of pollutant formation and destruction in combustion. Prog. Energy Combust. Sci. 1, 33-45. doi: 10.1016/0360-1285(75)90005-2

Bozzelli, J., and Dean, A. (1995). O + NNH: a possible new route for $\mathrm{NO}_{\mathrm{x}}$ formation in flames. Int. J. Chem. Kinet. 27, 1097-1109. doi: 10.1002/kin.550271107

Bubnovich, V., Henriquez, L., and Gnesdilov, N. (2007). Numerical study of the effect of the diameter of alumina balls on flame stabilization in a porous medium burner. Numer. Heat Transf. Part A Appl. 52, 275-295. doi: 10.1080/00397910601149942

Bubnovich, V., Martin, P. S., Henriquez, V. L., Orlovskaya, N., and Gonzaiez, H. A. R. (2016). Electric power generation from combustion in porous media. J. Porous Media 19, 841-851. doi: 10.1615/JPorMedia.v19.i10.10

Contarin, F., Saveliev, A. V., Fridman, A. A., and Kennedy, L. A. (2003). A reciprocal flow filtration combustor with embedded heat exchangers: numerical study. Int. J. Heat Mass Transf. 46, 949-961. doi: 10.1016/S0017-9310(02)00371-X

Dupont, V., and Williams, A. (1998). $\mathrm{NO}_{\mathrm{x}}$ mechanisms in rich methane-air flames. Combust. Flame 114, 103-118. doi: 10.1016/S0010-2180(97)00279-4

Ellzey, J. L., and Goel, R. (1995). Emissions of CO and NO from a two stage porous media burner. Combust. Sci. Technol. 107, 1-3. doi: 10.1080/00102209508907796 for $\mathrm{CO}$ concentration. The results indicate a decrease in $\mathrm{CO}$ concentration with increase in heat extraction temperature for both CFB and RCFB. Numerical simulations predict an increase in $\mathrm{CO}$ formation with rise in the equivalence ratio for both heat recirculating porous burners studied. This increase is due to rise in the hydrocarbon concentration at high equivalence ratios.

\section{DATA AVAILABILITY STATEMENT}

The datasets generated for this study are available on request to the corresponding author.

\section{AUTHOR CONTRIBUTIONS}

All authors listed have made a substantial, direct and intellectual contribution to the work, and approved it for publication.

Fenimore, C. P. (1971). Formation of nitric oxide in premixed hydrocarbon flames. Symp. Int. Combust. 13, 373-380. doi: 10.1016/S0082-0784(71)80040-1

Harrington, J. E., Smith, G. P., Berg, P. A., Noble, R. A., Jeffries, J. B., and Crosley, D. R. (1996). Evidence for a new NO production mechanism in flames. Symp. Int. Combust. 26, 2133-2138. doi: 10.1016/S0082-0784(96)80038-5

Hayhurst, A. N., and Hutchinson, E. M. (1998). Evidence for a new way of producing NO via NNH in fuel-rich flames at atmospheric pressure. Combust. Flame 114, 274-279. doi: 10.1016/S0010-2180(97)00328-3

Iverach, D., Kirov, N. Y., and Haynes, B. S. (1973). The formation of nitric oxide in fuel-rich flames. Combust. Sci. Technol. 8, 159-164. doi: 10.1080/00102207308946639

Kennedy, L. A., Bingue, J. P., Saveliev, A. V., Fridman, A. A., and Foutko, S. I. (2000). Chemical structures of methane-air filtration combustion waves for fuel-lean and fuel-rich conditions. Proc. Combust. Inst. 28, 1431-1438. doi: 10.1016/S0082-0784(00)80359-8

Kennedy, L. A., Saveliev, A. V., Bingue, J. P., and Fridman, A. A. (2002). Filtration combustion of a methane wave in air for oxygen-enriched and oxygen-depleted environments. Proc. Combust. Inst. 29, 835-841. doi: 10.1016/S1540-7489(02)80107-9

Khanna, V., Goel, R., and Ellzey, J. L. (1994). Measurements of emissions and radiation for methane combustion within a porous medium burner. Combust. Sci. Technol. 99, 133-142. doi: 10.1080/00102209408935429

Klippenstein, S. J., Harding, B. L., Glarborg, P., and Miller, J. A. (2011). The role of NNH in NO formation and control. Combust. Flame 158, 774-789. doi: 10.1016/j.combustflame.2010.12.013

Kotani, Y., and Takeno, T. (1982). An experimental study on stability and combustion characteristics of an excess enthalpy flame. Symp. Int. Combust. 19, 1503-1509. doi: 10.1016/S0082-0784(82)80327-5

Marbach, T. L., and Agrawal, A. K. (2005). Experimental study of surface and interior combustion using composite porous inert media. J. Eng. Gas Turbines Power 2005, 307-313. doi: 10.1115/1.1789516

Marteney, P. J. (1970). Analytical study of the kinetics of formation of nitrogen oxide in hydrocarbon-air combustion. Combust. Sci. Technol. 1, 461-469. doi: 10.1080/00102206908952226

Miller, J. A., and Bowman, C. T. (1989). Mechanism and modelling of nitrogen chemistry in combustion. Prog. Energy Combust. Sci. 15, 287-338. doi: 10.1016/0360-1285(89)90017-8

Smith, G. P., Golden, M. D., Frenklach, M., Moriarty, N. W., Eiteneer, B., Goldenberg, M., et al. (2009). Available online at: http://www.me.berkeley.edu/ gri_mech/

Steele, R. C., Tonouchi, J. H., Nicol, D. G., Homing, D. C., Malte, P. C., and Pratt, D. T. (1998). Characterization of $\mathrm{NO}_{\mathrm{x}}, \mathrm{N}_{2} \mathrm{O}$, and CO for lean-premixed combustion in a high-pressure jet-stirred reactor. J. Eng. Gas Turbines Power 120, 303-310. doi: 10.1115/1.2818121

Takeno, T., Sato, K., and Hase, K. (1981). A theoretical study on an excess enthalpy flame. Symp. Int. Combust. 18, 465-472. doi: 10.1016/S0082-0784(81)80052-5 
Toledo, M., Utria, K., Gonzalez, F., Zuniga, J., and Saveliev, A. V. (2012). Hybrid filtration combustion of natural gas and coal. Int. J. Hydrogen Energy 37, 6942-6948. doi: 10.1016/j.ijhydene.2012.01.061

Toledo, M., Vergara, E., and Saveliev, A. V. (2011). Syngas production in hybrid filtration combustion. Int. J. Hydrogen Energy 36, 3907-3912. doi: 10.1016/j.ijhydene.2010.11.060

Yao, Z., and Saveliev, A. V. (2018). High efficiency high temperature heat extraction from porous media reciprocal flow burner: time-averaged model. Appl. Therm. Eng. 143, 614-620. doi: 10.1016/j.applthermaleng.2018.07.144

Zeldovich, Y. B. (1946). Acta physicochim. USSR 21:577.
Conflict of Interest: The authors declare that the research was conducted in the absence of any commercial or financial relationships that could be construed as a potential conflict of interest.

Copyright (c) 2020 Banerjee and Saveliev. This is an open-access article distributed under the terms of the Creative Commons Attribution License (CC BY). The use, distribution or reproduction in other forums is permitted, provided the original author(s) and the copyright owner(s) are credited and that the original publication in this journal is cited, in accordance with accepted academic practice. No use, distribution or reproduction is permitted which does not comply with these terms. 